\title{
Research on the internet and check the status of e-banking in Iran
}

\author{
Morteza Ziaee \\ Department of Management, Ghorveh Branch, Islamic Azad University, Ghorveh, Iran \\ E-mail address: morteza_ziaee@yahoo.com
}

\begin{abstract}
E-banking is a special type of banking service to their customers to provide an electronic environment such as the Internet uses. This type of banking operations, including all of the bank receipt or deposit money, signature verification, inventory and other significant banking operations are conducted electronically. Internet Banking is a special kind of e-banking uses the Internet as a distribution channel. Two Popular models include electronic Reserve banks and branches electronics. Present age is communication and information technology age. One of the most important phenomena of this age is Revolutionizing of traditional banking. Development of electronic communication and access of large numbers of people to the Internet, has provided the conditions for establishing trade and economic exchanges. This subject led to increase of competition in the banking industry and creation of electronic banking services. With increasing demands for such services, something that should be considered is the barriers of electronic banking. In our research, we decided to check the status of ebanking in Iran. For this we have selected a number of banks. Questionnaire design and distribution between bank employees and its results interpreted.
\end{abstract}

Keywords: E-banking; Internet; Internet Banking; traditional banking

\section{INTRODUCTION}

Science and technology is egger to provide more facilities through their research and innovation in all fields of life. Internet is one of them that have become the integral part of life. Over the last few decades' information technology and it use has been increased (Saffu et al., 2008) and it has effected the banking industry in a way that banks can differentiate their products and services from others. Internet banking is not the new emergent concept it has encouraged many banks to rethink their It strategies in order to stay competitive, Eriksson et al., 2008. Internet banking is very useful and provides a convenient and useful approach to manage one's finances as it is easily accessible 24 hours a day, and seven days a week. Many developed and developing countries have adopted the internet banking. Pakistan is also developing country and trying to move towards internet banking. The major difference lies in the convenience offered by online banking particularly when it comes to making payments, obtaining updated information of the account, or integration account statements. Rather than personally visiting your local bank, you can now access your account and perform your bank transactions using your computer. At the comfort and privacy of your own home, you can now be able to complete various bank transactions with just a click of the mouse. But just like any 
other customer related services, traditional and online banking has its own shares of advantages and drawbacks which you should carefully consider. Customer choice between internet and land based banking service will depend on their priorities and the lifestyle they are familiar with. In Pakistan the trend towards adoption of internet banking is not as aggressive as it is in the rest part of the world. We cannot say that in Pakistan we don't have technology to implement the internet banking but there may be certain other reasons that could be the source of hindrance in adopting it, to identify those behavioral or technological reasons that decreases the customer satisfaction towards internet banking the researcher have conducted this study. Internet banking (or E-banking) means any user with a personal computer and a browser can get connected to his bank's website to perform any of the virtual banking functions. In internet banking system the bank has a centralized database that is web-enabled. All the services that the bank has permitted on the internet are displayed in menu. Once the branch offices of bank are interconnected through terrestrial or satellite links, there would be no physical identity for any branch. It would be a borderless entity permitting anytime, anywhere and anyhow banking. The network which connects the various locations and gives connectivity to the central office within the organization is called intranet. These networks are limited to organizations for which they are set up. SWIFT is a live example of intranet application.

\section{LITERATURE REVIEW}

\section{1. E-commerce}

For e-commerce as one of the great phenomenon of the 21 st century is presented, including different definitions can include:

All aspects of the market process that can be done with the Internet and Web technology, called electronic commerce. (Zargar, 2001) Generally, the term electronic commerce refers to transactions that are done through the communication network is implemented. First, the purchaser or consumer to search for a virtual shop on the Internet and good deals through the Web or mail order. The goods are finally delivered (Nykbkhsh Tehrani and others, 2002) Ecommerce means doing business transactions in electronic form. (Industry, 2001: 12) Application of information technology in business. (Ahmadi, 2001: 16) Europe Union in 1997, it was defined as follows: E-commerce and electronic processing and transmission of data including text, audio and video is based. Various activities such as e-commerce exchange of goods and services and the immediate delivery of digital content and electronic transmission are involved.

Commerce prior to that until recently was limited to a certain number of companies are entering a new era in which many consumers are present in the network. The content of the field order or order to exchange data beyond the major business activities such as advertising, advertising, negotiations, contracts and settlement of accounts is also derived. OECD point of view of electronic commerce, buying and selling goods and services between companies, individuals, governments and other public and private sectors so that the sale will be conducted through computer networks, is defined.

The e-commerce, technology, processing and collection of commercial operations at the time of the exchange network and automatically through the use of information technology has done well defined (Hyratsv, 2000). Chafy (2002), the concept of e-commerce can be defined from four perspectives:

A) communication perspective: a means of transferring information, goods, services or payments made by electronic means,

B) the business process perspective: the meaningful use of technology to automate the exchange and trade flows, 
C) point of service: synchronization means lower cost service, increased speed and quality of transport services,

D) to the point of view: the meaning of buying and selling information and products to you.

Set of definitions presented above can be concluded that the EC is much broader areas of exchange of goods and services and has funds in its definition and the policy should be considered in addition to the actual use of its potential applications will also. For e-commerce benefits and features that have been mentioned in a general category can be divided into following them.

- Globalization of trade

- remove the restrictions of time and place

- reducing the resources for the purchase price

- Increase the percentage of sales

- Easy access to information

- reducing transaction costs

- reduce transaction costs when

The content of e-commerce is not limited to order taking and order but the main business activities such as advertising, advertising, negotiations, contracts and liquidate its surrounds. E-commerce in traditional trade The advanced technology, creating new challenges for organizations is an opportunity. Changes in technology, changes in the law of commercial companies and transforming the social and organizational systems. Information technology to the leading edge of new technologies in the three parameters of speed, accuracy and cost of activities can be effective. Information technology can create five major advantages: cheaper (to produce the same output with lower cost), more (producing more output with the same cost), faster (to produce the same outputs at lower cost) better (and the cost of producing the same output but with e-commerce, geographical barriers and the difference between day and night in different areas, and improved communication and openness of the economy at national and international level is . conduct business through electronic commerce will change the traditional markets, and thus the conversion to the new forms (the same source, 2002: 17).While e-commerce website and especially the kind that has caused dramatic changes in competitive conditions (eg. the rapid advent of new competitors, competition, globalization, intense competition in the standards, etc.) for new opportunities to replace and work, creating jobs and new job opportunities in various fields has developed. Overall, the benefits of ecommerce compared to traditional trade as the following:

Presence in the market "is everywhere, everyone, all the time."

In promoting the product, the use of e-commerce, especially using the Internet, with limitations on conventional advertising is not available at any time and can be changed for any particular group of consumers. E-commerce sales will change the usual channels and the possibility of direct sales and through new products and services to new markets and provide strategies. Immediate on-line sales and sales costs and greatly reduces the need for manpower. Since the field is reduced and new products as soon as they get ready to be sold on line Service to customer can be on both sides of each Vrzh Khbrgyry fast customer services and facilities to be Completed. Electronic payment requirements, development and growth of electronic commerce. The growth of electronic commerce, electronic payment is not possible without a comprehensive development. On the other hand, a significant development in different regions of the world of electronic commerce and electronic financial transactions, one of the main reasons is the growth of global electronic payment (Shekhan, 1999: 14). Numerous advantages of the Internet, online payments and dynamic financial sector and banking, electronic payments can be considered as development of other reasons. Internet 
development in different regions of the world, provides a line of communication and widespread growth of electronic payments, has had an important role. Internet development in the coming years, the good prospects for cost reduction, sustainable and safe communication on the line and also introduced new methods and pay on-line help files. At least four types of e-commerce has had on the banking and financial sector. Are:

A) Banks and financial institutions of technology and business operations, e-commerce to deliver products to customers are using.

B) New business opportunities for banks and financial institutions to provide new services to support ecommerce have emerged.

C) International system has changed.

D) The role of central banks in monetary policy has changed.

Banks and financial institutions by introducing a different method of payment, credit, funds transfer and financing transactions, facilitate and promote domestic and international trade has been. Financial and banking sectors have advanced, efficient and up to date, the main characteristic is the leading developed economies and developing countries. Countries that typically have good macroeconomic performance, efficient power systems are paid . Financial and banking sector, leading activities and in all countries and the global economy is in the range and has an important role in the development of international trade and investment. E- bank owners in line with technological developments, have always tried to provide existing services more efficient methods and also new services are introduced. Bankers of the 1970s the mechanization of processes attempting to create a special network of banking and banking operations and cooperation between the bank and have a particular settlement. Although these measures will not involve customers and processes behind the counter, took over, but there are good grounds to bring the advent of new technologies and the Internet in the 1990s, the basis for the emergence of electronic banking and Internet banking to all processes, engineering processes and provide customer service line was this day (Shekhan, 1999: 20).

In this situation, the payment of a specific network, the network will open up. Or electronic tax payment is to provide financial services through a network of fixed line and wireless Internet and other computer networks to business and households. However, the use of electronic payment transactions to pay for off-line electronic devices in remote areas is also on. E-finance, including brokerage (stock), banking, financial markets and insurance, electronic finance, e-commerce and financial services as it is. E-Finance is one of the best ecommerce applications. As financial services, information, and in most cases, does not require physical delivery (Ibid, 1999: 27-26). Electronic financial services are rapidly expanding. Despite differences between countries in the infrastructure and regulations, the development of electronic financial integration can be seen. However, the tax position is different in different sectors (Ibid, 1999: 40). E-finance is different in different sectors. Most agencies can be influential in the markets in which on-line trading has become the norm. Electronic payments, the structure and nature of financial services has changed. Lower cost (marginal cost less), more speed, more diverse services and access to wider networks, including electronic tax benefits is considered. Moreover, the entry of new competitors (even outside the financial sector) service providers and more competition in the financial sector, increased competition has (Ibid, 1999: 46). Transaction security, privacy of individuals, making the legal framework (including reform of laws and regulations and commercial banking).

\section{2. Electronic Commerce and Information Technology}

Information technology, the performance of individuals, organizations and governments have transformed the economic and social affairs, and even change people's thinking. 
Education, health, industry and manufacturing, commerce, banking, investment services and even the leisure and entertainment are all overshadowed by the effects of changes in technology. Information technology creates new jobs, new industries and the successive creation and major changes in lifestyle has brought about. Day world charm close to each other, the interaction of cultures, and ... Examples of these outcomes. From a scientific viewpoint, the present knowledge of genetic engineering technology in the aerospace, construction and future leader of one of the three branches of human knowledge and civilization is one tomorrow.

Advances in information technology are so widespread that some of the experts, with phenomena such as "the invention of steam machines" are considered synonymous. The economic dimensions of the "importance of achieving rapid accurate information" is the key to success in global competition. E-commerce as one of the most important of which is derived from information technology advances have been achieved in light of the information technology (Mirab and others, 2003: 20).

\section{THE RESEARCH METHODOLOGY}

Because this study sought to determine and describe and identify factors affecting adoption of electronic banking customers Parsian Bank is among the descriptive nature of the survey - are correlated. The study population consists of all customers in the branches of Community Bank of the West as a kind of electronic banking facilities (internet) Community banks have used Data for this study were collected from the two following methods. The library in this study was to gather information about the history and literature of books and articles, dissertations, and search the Web sites is used. Field Methods: In order to collect the data needed to evaluate the factors affecting customers using Internet banking services from the field method is used. The questionnaires were distributed through the branches of Parsian Bank is attempting to collect data. The model tested in this study Pykaraynn, six operating usefulness, ease of use, fun to be in the field of electronic banking, security and confidentiality, quality of connection as we determine the factors affecting adoption of electronic banking for measure the effectiveness of each factor on the adoption of electronic banking Pykaraynn questionnaire has been used. E-banking transactions are much cheaper than branch or even phone transactions.

This could turn yesterdays competitive advantage .a large branch network - into a comparative disadvantage, allowing e-banks to undercut bricks-and-mortar banks. This is commonly known as the "beached dinosaur" theory. E-banks are easy to set up, so lots of new entrants will arrive Old-world systems, cultures and structures will not encumber these new entrants. Instead, they will be adaptable and responsive. E-banking gives consumers much more choice. Consumers will be less inclined to remain loyal. Portal providers are likely to attract the most significant share of banking profits. Indeed banks could become glorified marriage brokers. They would simply bring two parties together e.g. buyer and seller, payer and payee. The products will be provided by mono-lines, experts in their field. Traditional banks may simply be left with payment and settlement business even this could be cast into doubt. Traditional banks will find it difficult to evolve. Not only will they be unable to make acquisitions for cash as opposed to being able to offer shares, they will be unable to obtain additional capital from the stock market. This is in contrast to the situation for Internet firms for whom it seems relatively easy to attract investment. E-banking is just banking offered via a new delivery channel. It simply gives consumers another service (just as ATMs did).Experience in Scandinavia (arguably the most advanced e-banking area in the world) appears to confirm that the future is ,clicks and mortar ${ }^{\text {ee }}$ banking. Customers want full service 
banking via a number of delivery channels. The future is therefore „Martini Banking (any time, any place, anywhere, anyhow).

\section{HYPOTHESES}

There is relationship between bank cards and increase in bank income There is relationship between POS and increase in bank income

There is relationship between internet bank and increase in bank income

\section{RESEARCH METHODOLOGY}

\section{1. Research Method}

Since in this research, we will describe the factors effective on creation and development of electronic banking based on the viewpoints of 100 scholars and specialists accessible for us, this research is descriptive measuring and its goal is applied.

\section{2. Data collection method}

Data collection for this research was first done through library studies (books, papers, dissertations, internet texts) and then the researcher referred to some specialists and presented the related questionnaires to collect the data needed for this research. Also it should be noted that the measurement criterion in this research is Leikert's 5 points spectrum.

\section{3. Data analysis method}

To analyze the data, the inferential statistical methods were utilized. The researcher has first used t-student technique in multi-variable regression test to study the type of relationship between independent and dependent variables and then has used Freedman's test in order to rank each of the factors mentioned.

\section{TEST OF HYPOTHESIS RESEARCH}

In this stage of research, the relationship among all five variable ATM, pin pad, Pos, internet bank and telephone bank- with banks income is studied. ATM devices and bank income:

An ATM can acts like a bank branch and does lots of bank services without need of human interference. According to study result, there is effective relationship between ATM using and bank income with level of significance of $1 \%$ and it is about .464 in Pearson and $.407 \mathrm{a}$ Spearman and this relation is in average level of power. 
Table 1. The first hypothesis tests.

\begin{tabular}{|c|c|c|}
\hline & ATM & charge \\
\hline Pearson's correlation & 1 & $0 / 460$ \\
\hline ATM level of significance & 0 & $0 / 000$ \\
\hline $\mathrm{N}$ & 135 & 135 \\
\hline Pearson's correlation & $0 / 460$ & 1 \\
\hline $\begin{array}{c}\text { Level of significance of bank } \\
\text { income }\end{array}$ & $0 / 000$ & 0 \\
\hline $\mathrm{N}$ & 135 & 135 \\
\hline
\end{tabular}

Bank Card and bank income:

There is an effective relationship between bank card and bank income, but based on Spearman and Pearson tests the relation is in medium level.

Table 2. The second hypothesis tests.

\begin{tabular}{|c|c|c|}
\hline & Bank card & income \\
\hline Pearson's correlation & 1 & $0 / 480$ \\
\hline $\begin{array}{c}\text { of Bank card level of } \\
\text { significance }\end{array}$ & 0 & $0 / 000$ \\
\hline $\mathrm{N}$ & 135 & 135 \\
\hline Pearson's correlation & $0 / 480$ & 0 \\
\hline $\begin{array}{c}\text { Level of significance of } \\
\text { bank income }\end{array}$ & $0 / 000$ & 135 \\
\hline $\mathrm{N}$ & 135 & \\
\hline
\end{tabular}

Internet bank and bank income:

There is effective relation between Internet bank and bank income.

Table 3. The third hypothesis tests.

\begin{tabular}{|c|c|c|}
\hline & Internet bank & charge \\
\hline Pearson's correlation & 1 & $0 / 701$ \\
\hline $\begin{array}{c}\text { level of significance of } \\
\text { Internet bank }\end{array}$ & 0 & $0 / 000$ \\
\hline $\mathrm{N}$ & 135 & 135 \\
\hline Pearson's correlation & $0 / 701$ & 0 \\
\hline $\begin{array}{c}\text { Level of significance of } \\
\text { bank income }\end{array}$ & $0 / 000$ & 135 \\
\hline $\mathrm{N}$ & 135 & 1 \\
\hline
\end{tabular}




\section{CONCLUSIONS}

In the first part of recent decade, globe banks have prepared stable condition - low banking rate, increase in accommodation price, loan - that allow them to have a rudiment growth and provide value for their shareholder. Most of the banks were able to improve their income and their charge. It was obvious that credit flawing, giving loan would have many problems. But today, expensive energy price, economic instill, and constant decreasing in credit cause balance. Focus on growth with the loss of performance discipline; simplifying products; budget and organizational configuration pose more complex performance models that in their place make extensive charges and different functions. The near sight perspective isn't promising. There is a tremendous pressure over south America and western European banks due to loan loss and slow rate growth or even negative growth of income (due to fragile accommodation issues). Fortunately, lots of Asian banks, Pacific Ocean zone, and central and eastern banks of Europe are incapable to such confusion. But some banks are affected dramatically from the economic loss. Their costs are more than their income and they have budget problem. Efforts on seizing these problems with the help of increasing investment and share profit aren't successful. The banks are also going to decrease their staff charges and due to this matter many people around the world last thir jobs. In the positive perspective, the current environment gives joyful opportunity to new banks especially those with new emergence Brazil, china, India, and Russia. So the new banks should have powerful common sense by decreasing their charges to be able to work in accompany with global banks, and this should be in a way that doesn't endanger their future plans. To decrease in IT employee seems logical. It is because of the importance of IT in banking system. The study of using IT in banking indicates that by using of each IT tools we can decrease the banking transaction. It is meant that by using E- banking instead of traditional banking system we can decrease the charges. Using IT in banking decrease risk taking management, increasing security, and decrease time wasting as well as.

\section{References}

[1] Aladvani Adel M., "Online Banking: A Field Study of Drives Development, Challenges and Expectations, International Journal of Information Management 21 (2001) 213-225.

[2] Lewis W. G., Pun K. F., Lalla T. R. M., International Journal of Productivity and Performance Management 55(7) (2006) 539-554.

[3] Embrechts P., Kluppelberg C., Mikosch T., Modeling External Events for Insurance and Finance, New York: Pringer Verlag (1997).

[4] Ivan Soukala, Martina Hedvicakov, Retail core banking services e-banking client cluster identification, Procedia Computer Science 3 (2011) 1205-1210.

[5] Laukkanen T., Internet VS mobile banking: comparing customer value perceptions, Business process management journal 13(6) (2007) 788-797.

[6] Mehdi Alinezhad Sarokolaei, Akbar Rahimipoor, Sayyad Nadimi, Masomeh Taheri, The investigating of barriers of development of e-banking in Iran, Procedia - Social and Behavioral Sciences 62 ( 2012 ) 1100-1106.

[7] Ming Huo, Lio Beng, Soon Chong Islamic Banking: Interest-Free or Interest-Based?", Pacific-Basin Finance Journal Forthcoming (2005) 2-39. 
[8] Shilpan Vyas, Impact of E-Banking on Traditional Banking Services, School of Computer Science and Information Technology Gupta V, (2002).

[9] W. G. Lewis, K. F. Pun, T. R. M. Lalla, Exploring Soft Versus Hard Factors for TQM Implementation in Small and Medium-Sized Enterprises, International Journal of Productivity and Performance Management 55(7) (2006) 539-554.

[10] Ziaee Morteza, International Letters of Social and Humanistic Sciences 9 (2014) 57-65.

[11] Ziaee Morteza, International Letters of Social and Humanistic Sciences 10(1) (2014) $36-43$. 